the world's oceans. Clearly a strong lead is required from an international environmental organization such as UNEP if this problem is to be seriously tackled. Only in this way can satisfactory pollution control measures for plastic waste become the norm and be effective.

Addison, R. F. (1976). Organochlorine compounds in aquatic organisms: there distribution, transport and physiological significance. In Effects of Pollutants on Aquatic Organisms (Edited by A. P. M. Lockwood), pp. 127-143, Cambridge University Press.

Carpenter, E. J. \& Smith, K. L. (1972). Plastic on the Sargasso Sea surface. Science, N.Y., 175, 1240-1241.

Carpenter, E. J., Anderson, S. J., Harvey, G. R., Miklas, H. P. \& Peck, B. P. (1972). Polystyrene spherules in coastal waters. Science, N.Y., 178, 749-750,

Colton, J. B., Knapp, F. D. \& Burns, B. R. (1974). Plastic particles in surface water of the northwestern Atlantic. Science, N.Y., 185, 491-497.

David, P. (1975). The neuston net. A device for sampling the surface fauna of the ocean. J. mar. biol. Ass. U.K., 45,313-320.
Elder, D. L. \& Villeneuve, J. P. (1977). Polychlorinated biphenyls in the Mediterranean Sea. Mar. Pollut. Bull. 8, 19-22.

Fowler, S. W. \& Elder, D. L. (1978). PCB and DDT residues in a Mediterranean pelagic food chain. Bull. Envir. contam. Toxicol., 19, 244-249.

Giam, C. S., Chan, H. S. \& Neff, G. S. (1978). Phthalate ester plasticizers, DDT, DDE and polychlorinated biphenyls in biota from the Gulf of Mexico. Mar. Pollut. Bull., 9, 249-251.

Gregory, M. R. (1977). Plastic pellets on New Zealand beaches, Mar. Pollut. Bull., 8, 82-84.

Hays, H. \& Cormons, G. (1974). Plastic particles found in tern pellets on coastal beaches and at factory sites. Mar. Pollut. Bull., 5, 44-46.

Kartar, S., Milne, R. \& Sainsbury, M. (1973). Polystyrene waste in the Severn Estuary. Mar. Pollut. Bull., 4, 144.

Kartar, S. Abou-Seedo, F.\& Sainsbury, M. (1976). Polystyrene spherules in the Severn Estuary - a progress report. Mar. Pollut. Bull., 7, 52.

Marine Pollution Bulletin (1975). Plastic cups found in fish. 6, 148.

Morris, A. W. \& Hamilton, E. I. (1974). Polystyrene spherules in the Bristol Channel. Mar. Pollut. Bull., 5, 26-27.

Morris, R. J. (1970) Phthalic acid in the deep sea jellyfish Atolla. Nature, Lond., 227, 1264.

Shiber, J. G. (1979). Plastic pellets on the coast of Lebanon. Mar. Pollut. Bull., 10, 28-30.

\title{
Abnormal Development of Dentalium due to the Amoco Cadiz Oil Spill
}

\author{
A. SJ. KOSTER and J. A. M. VAN DEN BIGGELAAR \\ Station Biologique, 29211 Roscoff, France and Zoological Laboratory, State University of Utrecht, \\ Padualaan 8, 3508 TB Utrecht, The Netherlands* \\ *Correspondence should be addressed to the latter address.
}

\begin{abstract}
A comparison was made between the development of Dentalium eggs, spawned by animals, collected before and after the Amoco Cadiz oil spill. Development of eggs from animals collected before the oil spill was significantly better than development of eggs from animals collected after the oil spill. It is suggested that development is affected by oil hydrocarbons, accumulated during oogenesis in the lipidrich phases of the oocytes.
\end{abstract}

During our stay at the Station Biologique at Roscoff in August 1978, the planned embryological investigations with Dentalium vulgare have been continuously frustrated by abnormal development of the embryos. There are, however, some results suggesting that this might be due to the Amoco Cadiz oil spill in March 1978.

By coincidence, a number of females of Dentalium were kept from July 1977 in the running sea-water system of the laboratory, thus escaping the oil-contamination in their natural habitat. This fortunate circumstance enabled us to make a comparison between the development of embryos and larvae from oocytes of females, collected before and after the oil spill. The results reported here indicate that the disturbances of normal development may be explained by accumulation of oil hydrocarbons in the oocytes.

\section{Materials and Methods}

Dentalium vulgare (da Costa) (Scaphopoda, Mollusca) was collected in the Bay of Morlaix, 300-400 m North of ' $\mathrm{La}$ Vieille' (depth $25-30 \mathrm{~m}$ ) and kept in the laboratory in a layer of bottom-grit, either in running sea-water at $17^{\circ} \mathrm{C}$ or in daily changed sea-water at $12^{\circ} \mathrm{C}$. The animals, collected in 1977 passed the winter in running seawater in the aquarium of the laboratory. Spawning was induced by transferring the animals to glass containers (with about $100 \mathrm{ml}$ of sea-water), left to equilibrate to room temperature. Oocytes were fertilized by adding a sperm suspension of adequate dilution. Cleaving embryos and larvae were kept in millipore-filtered sea-water, which was changed daily.

\section{Results}

As a rule, fertilization of oocytes spawned by females freshly collected in 1978 was extremely poor. In the batches of oocytes, in which fertilization succeeded, no more than $30 \%$ of the eggs started cleavage; adding more sperm in these cases did not improve fertilization rate. First cleavage in about $20 \%$ of the cases was abnormal. The following deviations of normal cleavage were seen: retarded cleavage, inequal cleavage and/or premature regression of the polar lobe constriction and regression of cleavage furrows. 
Trochophores, formed $25 \mathrm{~h}$ after first cleavage, were frequently malformed. Development was retarded and the trochophores were swimming slowly and were incoordinated. Mortality of trochophores was marked (up to $100 \%$ in some batches). The larvae, which metamorphosed normally, seemed to be affected no more.

One experiment needs special attention. Oocytes were obtained from females, collected before and after the oil spill (i.e. in 1977 and 1978, respectively). These batches of oocytes were fertilized each with an equal amount of the same sperm-suspension, obtained from males collected in 1978. While the percentage of fertilization was low in both cases, development of eggs spawned by females collected in 1977 was significantly better than development of eggs, spawned by females collected in 1978 (Table 1). For reasons of brevity the first groups of larvae will be designated 1977larvae, while the latter will be called 1978-larvae.

The 1977-larvae are regularly formed (Figs 1 and 2(a)). The prototroch forms a continuous belt and a foot can be clearly distinguished. The pretrochal region is small in these larvae (compare Kowalewsky, 1883; Lacaze-Duthiers, $1856,1857)$. The trochophores are swimming rapidly and coordinated near the water-surface. The 1978-larvae, in contrast, are irregularly formed (Figs 1 and 2 (b) and (c)). The prototroch is less pronounced than in the 1977-larvae, while the foot and posttrochal region cannot always be clearly delineated. The pretrochal region is larger than in the 1977-larvae. The trochophores are swimming badly coordinated; they are turning around and rotating near the bottom of the culture vessel without any recognizable direction.

The eggs spawned by animals collected in 1979 developed normally. Therefore, the development of Dentalium seems to be affected only the first reproductive season after the oil spill.

\section{Discussion}

After adding water-soluble fractions of different oils to the sea-water, low percentage of fertilization, poor development of embryos and mortality of larvae of the sand dollar and some species of marine bivalves has been observed (Renzoni, 1975; Byrne \& Calder, 1977; Nicol et al., 1977; Nunes \& Benville, 1978). Vacuolization of embryos and inability to swim has been described for Mulinia larvae under experimentally oiled conditions (Renzoni, 1975). The concentrations of hydrocarbons, causing these effects are in the range of $0.1-10 \mathrm{mg} \mathrm{l}^{-1}$ As the concentration of oil hydrocarbons, measured in the sea-water at Roscoff in July 1978 was $0.02 \mathrm{mg} \mathrm{l}^{-1}$ maximally (Cabioch, personal communication), it is unlikely that the poor development of Dentalium embryos and larvae reported here, is due to the presence of oil hydrocarbons in the sea-water. Furthermore, normal development of the 1977-larvae confirms that oil hydrocarbons, if present in the sea-water, are not directly responsible for causing a disturbance of development. Possibly, the low percentage of fertilization can be explained in that way (sperm being sensitive to much lower concentrations of oil hydrocarbons than oocytes (Renzoni, 1975; Nicol et al., 1977).

A more feasible hypothesis to explain the observed disturbances in the development of Dentalium eggs is that abnormal morphogenesis is caused by oil hydrocarbons, accumulated in the oocytes. Accumulated hydrocarbons are likely to cause malformations similar to hydrocarbons, added to the sea-water. In both cases the hydrocarbons are affecting development indirectly by their incorporation in lipid-rich phases of the embryos (lipid-yolk and membranes). Abortion of lobster-eggs, due to oil hydrocarbon accumulation following the Amoco Cadiz oil spill is reported (Laubier, 1978).

Unfortunately, no data about the composition of Dentalium oocytes are available. In general, however, the ovaries of marine molluscan species have high lipid contents, which increase during oogenesis (Williams, 1970; Webber, 1970; Lawrence, 1976). In Dentalium oogenesis occurs in spring, the oocytes being mature from June till September. Similar to the oocytes of marine molluscan species, the eggs of the polychaete Nereis are very rich in neutral lipids (Pocock et al., 1971). Under experimental conditions oil hydrocarbons are specifically accumulated in the oocytes of the polychaete Neanthes (Rossi \& Anderson, 1977).

The sediment from which Dentalium was collected is known to be contaminated by oil hydrocarbons. In August 1978 (i.e. 5 months after the oil spill) concentrations of about $30 \mathrm{mg} \mathrm{kg}^{-1}$ dry weight were measured (Cabioch, personal communication). It is feasiable that this sedimentcontamination causes low levels of oil hydrocarbons in the interstitial water for a long period (Cabioch et al., 1978).

TABLE 1

Development of embryos and larvae of Dentalium vulgare from oocytes, spawned by females collected in 1977 and 1978 . The batches of oocytes were fertilized with an equal amount of the same sperm-suspension, spawned by males collected in 1978.

\begin{tabular}{|c|c|c|c|c|c|c|}
\hline & \multicolumn{3}{|c|}{ Development up to fourth cleavage } & \multicolumn{3}{|c|}{ Development of trochophores $(95 \mathrm{~h})$} \\
\hline & $\begin{array}{c}\text { No } \\
\text { cleavage }\end{array}$ & $\begin{array}{l}\text { Abnormal } \\
\text { cleavage* }\end{array}$ & $\begin{array}{l}\text { Normal } \\
\text { cleavage }\end{array}$ & Dead & Abnormal $\uparrow$ & Normal $\ddagger$ \\
\hline $\begin{array}{l}\text { A, Oocytes from females collected in } \\
\text { July } 1977 \text {, kept at } 17^{\circ} \mathrm{C}\end{array}$ & $\begin{array}{l}100 / 140 \\
(72 \%)\end{array}$ & $\begin{array}{l}5 / 140 \\
(4 \%)\end{array}$ & $\begin{array}{l}33 / 140 \\
(24 \%)\end{array}$ & $\begin{array}{r}7 / 33 \\
(21 \%)\end{array}$ & $\begin{array}{r}2 / 33 \\
(6 \%)\end{array}$ & $\begin{array}{r}24 / 33 \\
(73 \%)\end{array}$ \\
\hline $\begin{array}{l}\text { B. Oocytes from females collected in } \\
\text { August } 1978 \text {, kept at } 17^{\circ} \mathrm{C}\end{array}$ & $\begin{array}{c}138 / 183 \\
(75 \%)\end{array}$ & $\begin{array}{l}5 / 183 \\
(4 \%)\end{array}$ & $\begin{array}{l}38 / 183 \\
(21 \%)\end{array}$ & $\begin{array}{l}26 / 38 \\
(68 \%)\end{array}$ & $\begin{array}{l}12 / 38 \\
(32 \%)\end{array}$ & $\begin{array}{c}0 / 38 \\
(0 \%)\end{array}$ \\
\hline $\begin{array}{l}\text { C. Oocytes from females collected in } \\
\text { August } 1978, \text { kept at } 12^{\circ} \mathrm{C}\end{array}$ & $\begin{array}{c}310 / 345 \\
(90 \%)\end{array}$ & $\begin{array}{c}11 / 345 \\
(3 \%)\end{array}$ & $\begin{array}{c}24 / 345 \\
(7 \%)\end{array}$ & $\begin{array}{r}8 / 24 \\
(33 \%)\end{array}$ & $\begin{array}{l}16 / 24 \\
(67 \% 07\end{array}$ & $\begin{array}{r}0 / 24 \\
(0 \%)\end{array}$ \\
\hline
\end{tabular}

*Polyspermic eggs not included.

† Trochophores are swimming uncoordinated near the bottom of the culture vessel. The larvae are irregularly formed (see Figs 1 and 2 (b) and (c)).

\$ Trochophores are swimming rapidly near the water surface. The larvae are regularly formed (see Figs 1 and 2 (a)). 


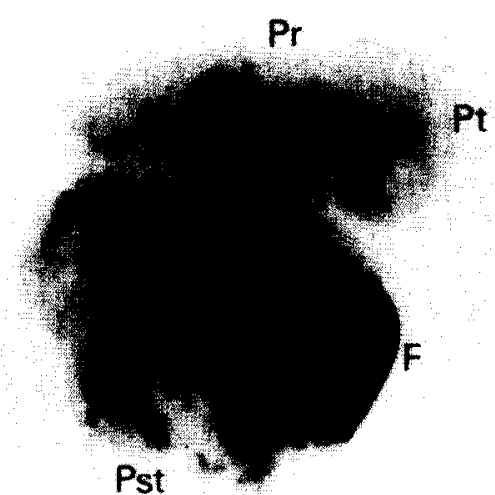

$A-L$

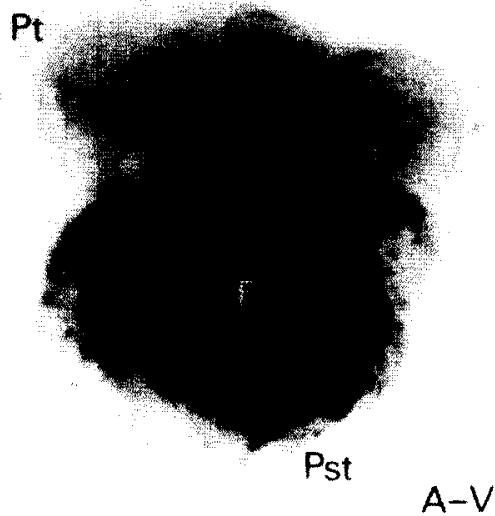

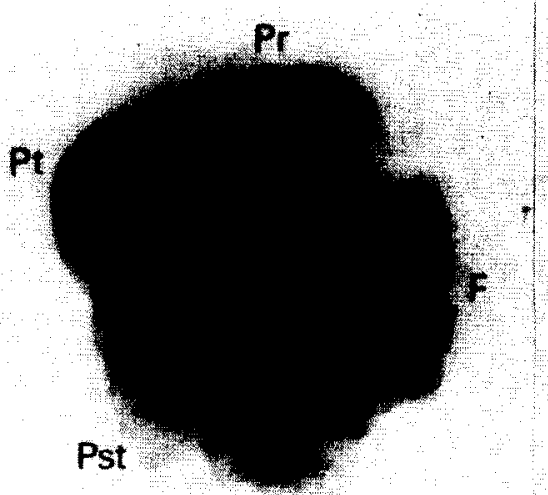

B-L

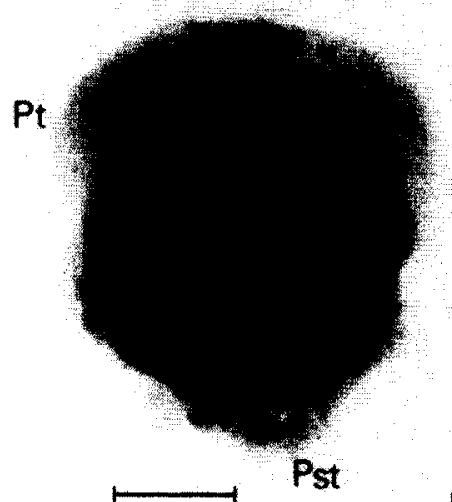

$B-V$

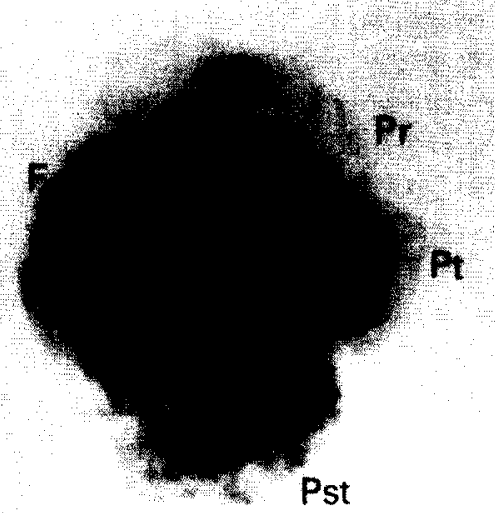

C-L

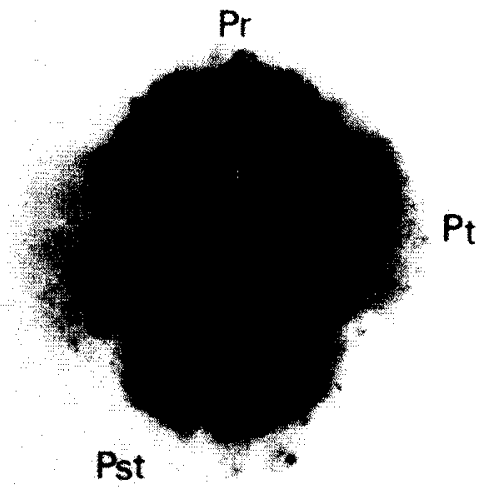

$\mathrm{C}-\mathrm{V}$

Fig. 1 Trochophores ( $50 \mathrm{~h}$ after first cleavage) of Dentalium vulgare developed from oocytes, spawned by females collected in 1977 (a) and 1978 (b) and (c). The females were kept at $12^{\circ} \mathrm{C}(\mathrm{c})$ or $17^{\circ} \mathrm{C}(\mathrm{a})$ and $(\mathrm{b})$. Each larva is seen from the lateral (L) and ventral $(\mathrm{V})$ side. $\mathrm{F}=$ foot $\mathrm{Pr}=$ pretrochal region, $\mathrm{Pst}=$ posttrochal region, $\mathrm{Pt}=$ prototroch. The larvae were fixed in zenker and stained with gallocyanin $(0.15 \%$ in $15 \%$ chrome-alum, pH 0.84). Scale: $0.2 \mathrm{~mm}$.

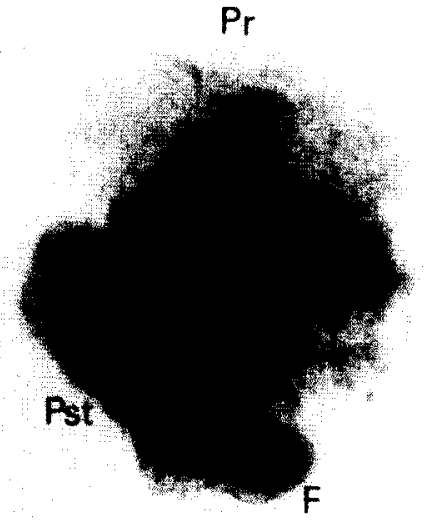

1

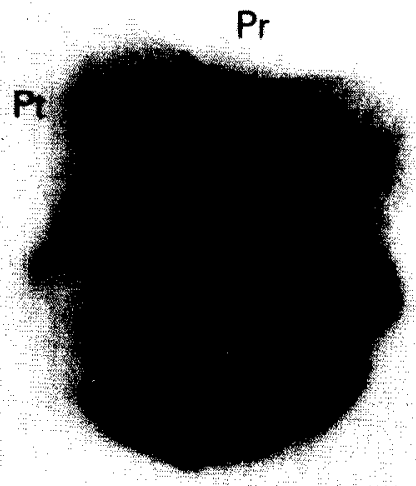

Pt

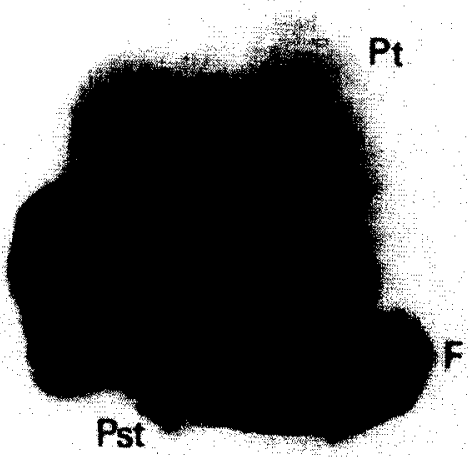

B-L

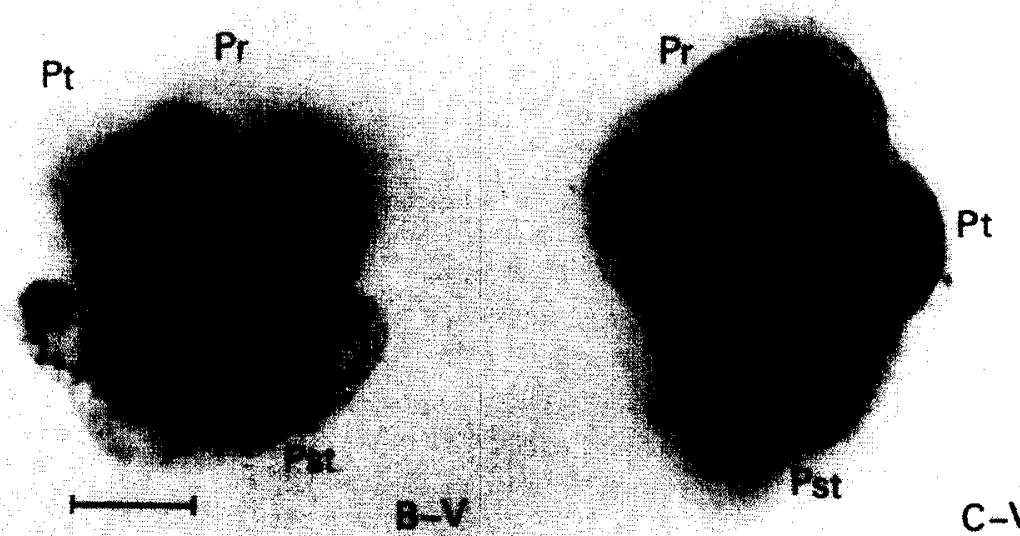

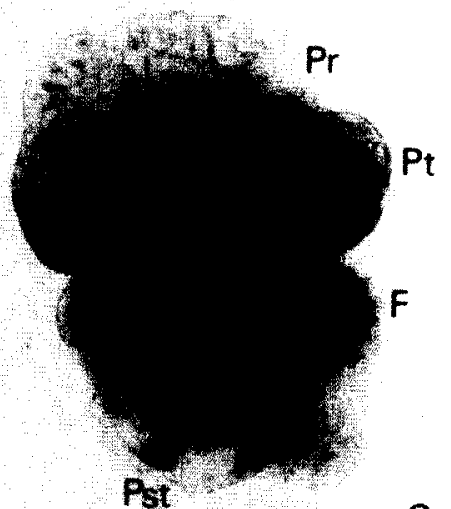

$C-L$
$A-L$

A-V

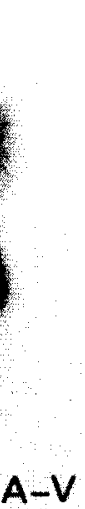

Fig. 2 Trochophores ( $70 \mathrm{~h}$ after first cleavage) of Dentalium vulgare developed from oocytes, spawned by females collected in 1977 (a) and 1978 (b) and (c). The females were kept at $12^{\circ} \mathrm{C}$ (c) or $17^{\circ} \mathrm{C}$ (a) and (b). Each larva is seen from the lateral (L) and ventral (V) side. $F=$ foot, $\mathrm{Pr}=$ pretrochal region, $\mathrm{Pst}=$ posttrochal region, $\mathrm{Pt}=$ prototroch. The larvae were fixed in Zenker and stained with gallocyanin $(0.15 \%$ in $15 \%$ chrome-alum, pH 0.84). Scale: $0.2 \mathrm{~mm}$. 
During long-term exposure to sea-water, containing relative small amounts of oil hydrocarbons, molluscan species accumulate these hydrocarbons in considerable amounts. Concentration-factors as high as 1000 have been reported (Stegeman, 1974, Grahl-Nielsen et al., 1978; Roesijadi et al., 1978). Another way by which oil hydrocarbons could be accumulated is via the marine food web (Blumer et al., 1970). With regard to Dentalium it is not clear to what extent both processes could attribute to possible accumulation of oil hydrocarbons (see Morton, 1959).

Summarizing, it is feasible that oil hydrocarbons, deposited in the sediment of the Bay of Morlaix, are accumulated in the oocytes of Dentalium during oogenesis, either via ingested material or via direct absorption from the interstitial water. These accumulated hydrocarbons can disturb morphogenesis by their incorporation in the lipidyolk and the membranes. These disturbances of embryogenesis probably will have no long-lasting effects on the population-dynamics of this species, because development appeared to be normal in animals collected in the second reproductive season following the oil spill.

The work reported here was supported by a grant from the Netherlands Ministry of Education and Sciences. The authors wish to thank Professor Dr J. Bergerard for the hospitality at the Biological Station of Roscof $f$ and Dr L. Cabioch for commenting upon the manuscript. $\mathrm{Mr} \mathrm{H}$. van Kooten and $\mathrm{Mr}$ J. J. van der Vlis are gratefully acknowledged for preparing the figures.

Blumer, M., Mullen, M. M. \& Guillard, R. R. L. (1970). A polyunsaturated hydrcarbon $(3,6,9,12,15,18$-heneicosahexaene) in the marine food-web. Mar. Biol., 6, 226-235

Byrne, C. J. \& Calder, J. A. (1977). Effects of water soluble fractions of crude, refined and waste oils on the embryonic and larval stages of the quahog clam, Mercenaria sp. Mar. Biol., 40, 225-231
Cabioch, L., Dauvin, J -C. \& Gentil, F. (1978). Preliminary observation on the pollution of the sea bed and disturbance of sub-littoral communities in northern Brittany by oil from the Amoco Cadiz. Mar. Pollut. Bull., 9, 303-307.

Grahl-Nielsen, O., Staveland, J. T. \& Wilhelmsen, S. (1978). Aromatic hydrocarbons in benthic organisms from coastal areas polluted by Iranian crude oil. J. fish. Res. Bd Can., 35, 615-623.

Kowalewsky, A. (1883). Étude sur l'embryologie du Dentale. Ann. Mus. Hist, nat Marseille Zool 1 (7).

Lacaze-Duthiers, H. de $(1856,1857)$. Histoire de l'organisation et du développement du Dentale. Ann. Sci. nat, (4 éme Série), 6 \& 7.

Laubier, K. (1978). The Amoco Cadiz oil spill - lines of study and early observations. Mar. Pollut. Bull., 9, 285-287.

Lawrence, J. M. (1976). Patterns of lipid storage in post-metamorphic marine invertebrates. Am. Zool., 16, 747-762.

Morton, J. E. (1959). The habits and feeding organs of Dentalium entalis. J. Mar. Biol. Ass, U.K., 38, 225-238.

Nicol., J. A. C., Donahue, W. H., Wang, R. T. \& Winters, K. (1977), Chemical composition and effects of water extracts of petroleum on eggs of the sand dollar Melitta quinquiesperforata. Mar. Biol., 40, 309-316.

Nunes, P. \& Benville, P. E. (1978). Acute toxicity of the water-soluble fraction of Cook Inlet crude oil on the Manila clam. Mar. Pollut. Bull. 9, 324-331.

Pocock, D. M. E., Marsden, J. R. \& Hamilton, J. G. (1971). Lipids in an intertidal polychaete and their relation to maturation of the worm. Comp. Biochem. Physiol. 39A, 683-697.

Renzoni, A. (1975). Toxicity of three oils to bivalve gametes and larvae. Mar. Pollut. Bull., 6, 125-128.

Roesijadi, G., Anderson, J. W. \& Blaylock, J. W. (1978). Uptake of hydrocarbons from marine sediments contaminated with Prudhoe Bay crude oil: influence of feeding type of test species and availability of polycyclic aromatic hydrocarbons. J. fish. Res. Bd Can., 35, 608-614.

Rossi, S. S. \& Anderson, J. W. (1977). Accumulation and release of fueloil-derived diaromatic hydrocarbons by the polychaete Neanthes arenaceodentata. Mar. Biol., 39, 51-55.

Stegeman, J. J. (1974). Hydrocarbons in shellfish chronically exposed to low levels of fuel oil. In Pollution and Physiology of Marine Organisms (Edited by F. J. Vernberg and W. B. Vernberg). pp. 329-347. Academic Press, New York.

Webber, H. H. (1970). Changes in metabolite composition during the reproductive cycle of the abalone Haliotis cracheroidii (Gastropoda: Prosobranchiata). Physiol. Zool., 43, 213-231.

Williams, E. E. (1970). Seasonal variations in the biochemical composition of the edible winkle Littorina littorea (L.). Comp. Biochem. Physiol., 33, 655-661.

\title{
Effect of Non-Petroleum Oil Spills on Wintering Birds near Vancouver
}

\author{
RICHARD W. McKELVEY*, IAN ROBERTSON $\uparrow \neq$ and PHILIP E. WHITEHEAD $\S$ \\ *Department of Environment, Canadian Wildlife Service, Box 340, Delta, British Columbia, Canada V4K 3 Y 3 \\ + Department of Fisheries and Environment, Environmental Protection Service, 4th Floor, Kapilano 100, \\ West Vancouver, British Columbia, Canada V7T IA2 \\ §epartment of Environment, Canadian Wildlife Service, Vivarium, University of B.C. Campus, Vancouver, \\ British Columbia, Canada V6T 1 W5 \\ $\neq$ Present address: Beak Consultants Limited, Suite 602, 1550 Alberni Street, Vancouver, British Columbia, \\ Canada V6G 1A5
}

\begin{abstract}
Within the period of our records, spills of vegetable oils at Vancouver harbour have caused greater losses of birds than spills of petroleum oils. Vegetable oils affect birds by feather wetting but do not exhibit odour and slick characteristics of petroleum oils. Because most vegetable oils are edible their potential danger to aquatic birds may go unnoticed; sites of storage and transhipment of vegetable oils may be overlooked in oil spill contingency planning.
\end{abstract}

The danger of oil pollution to aquatic birds is widely acknowledged; petroleum oils are well known for their ability to reduce or eliminate feather water-proofing, resulting in exposure and ultimately death. However petroleum products are not the only potential source of oil pollution to aquatic birds. Recently, the greatest effects of oil pollution on birds in the harbour at Vancouver, British Columbia, have come from two small spills of vegetable oils. 